\title{
O trabalho e a saúde dos oficiais de Justiça Federal de Porto Alegre
}

\author{
Álvaro Roberto Crespo Merlo ${ }^{\mathrm{I}, 1}$, Rogério Alexandre Nedir Dornelles ${ }^{\mathrm{II}, 2}$, \\ Carla Garcia Bottega ${ }^{\mathrm{I}, 3}$ e Laís Trentini ${ }^{\mathrm{I}, 4}$ \\ ${ }^{\mathrm{I}}$ Universidade Federal do Rio Grande do Sul (Porto Alegre, RS) \\ II Sindicato dos Trabalhadores da Justiça Federal do Rio Grande do Sul (Porto Alegre, RS)
}

\begin{abstract}
Este artigo apresenta resultados de pesquisa que investigou os efeitos do trabalho sobre a saúde de oficiais de Justiça Federal de Porto Alegre. A demanda partiu do Sindicato dos Trabalhadores da Justiça Federal do Rio Grande do Sul (Sintrajufe-RS), devido ao aumento das queixas relacionadas à saúde desses servidores. Foi utilizado um questionário estruturado, o Self Report Questionnaire (SRQ-20), para pesquisar a prevalência de distúrbios psiquiátricos menores e a metodologia da Psicodinâmica do Trabalho, com modelo metodológico de pesquisa-ação. Os resultados obtidos apontam que o principal problema está relacionado à falta de reconhecimento do trabalho realizado por esses profissionais. Também foram relatadas pelo grupo questões de desrespeito em relação ao exercício de sua atividade e o trabalho solitário. Sugere-se um espaço de discussão/reunião que envolva os trabalhadores, a coordenação e a representação do juiz, com participação de profissionais da Psicologia, caracterizando uma ação permanente.
\end{abstract}

Palavras-chave: Saúde do trabalhador, Psicodinâmica do trabalho, Oficiais de Justiça.

Work and health of the Federal Justice officials at Porto Alegre

This paper presents results from a research which investigated the effects of work on the health of Federal Justice officials at Porto Alegre. The demand emerged from the Union of Workers of the Federal Justice of Rio Grande do Sul (Sintrajufe-RS), due to increased complaints with regard to the health of these servants. A structured questionnaire was used, the Self Report Questionnaire (SRQ-20), in order to survey the prevalence of minor psychiatric disorders and the methodology of Work Psychodynamics, with a methodological model of researchaction. The results obtained point out that the main problem is related to a lack of recognition to the work performed by these professionals. Issues of disrespect with regard to their activity and solitary work were also reported by the group. One suggests a discussion/meeting space involving the workers, the coordination, and the judge's representation, with the participation of Psychology professionals, characterizing a permanent action.

Keywords: Occupational health, Work Psychodynamics, Justice officials.

\section{Introdução}

$\mathrm{O}$ trabalho, produtor de modos de subjetivação que expressam as formas de viver em determinado período histórico, é um importante referencial para o desenvolvimento emocional, psíquico e cognitivo do indivíduo, além de contribuir para seu reconhecimento social. Em função disso, sua importância é cada vez mais relevante para a vida das pessoas, ocupando uma posição central no mundo contemporâneo. Contudo, pode-se dizer que representa um elemento paradoxal para o ser humano, uma vez que, além de gerar prazer e realização, também é fonte de sofrimento, podendo, assim, levar ao adoecimento (Dejours, 2004). Por isso, condições favoráveis à livre utilização das habilidades e das potencialidades criativas têm sido identificadas como importante requisito para que o trabalho possa proporcionar bem-estar, prazer e, consequentemente, saúde.

1 Professor Associado da Universidade Federal do Rio Grande do Sul (UFRGS).

2 Médico do trabalho. Sindicato dos Trabalhadores da Justiça Federal do Rio Grande do Sul (Sintrajufe-RS).

3 Doutoranda em Psicologia Social e Institucional na UFRGS.

4 Acadêmica de Psicologia. Bolsista de Iniciação Científica na UFRGS. 
O Sindicato dos Trabalhadores da Justiça Federal do Rio Grande do Sul (SintrajufeRS) vem acompanhando um aumento nas queixas relacionadas à saúde por parte dos servidores - em especial oficiais de Justiça -, e, em muitos casos, relacionadas com o trabalho. A partir disso, em parceria com a Universidade Federal do Rio Grande do Sul (UFRGS), através do Centro de Documentação, Pesquisa e Formação em Saúde e Trabalho (Cedop), da Faculdade de Medicina, e do Laboratório de Psicodinâmica do Trabalho (LPdT), do Programa de Pós-Graduação em Psicologia Social e Institucional, elaborou uma proposta de investigação que pudesse responder, de forma científica, as questões levantadas pela demanda. Esse estudo se justifica porque o trabalho e suas relações são o que permite o confronto entre o mundo objetivo e a singularidade de cada trabalhador. Nessa complexidade de relações, o conflito entre organização do trabalho e subjetividade do trabalhador é gerador de sofrimento psíquico, pois o sujeito está constantemente tentando manter sua saúde mental, utilizando-se, quando possível, de potencialidades e de estratégias defensivas coletivas (Dejours, 2004).

Os oficiais de Justiça são servidores públicos federais que ingressaram no trabalho por meio de concurso público. Segundo Ellwanger (2009), o oficial de Justiça avaliador federal, bacharel em Direito, atua no Judiciário Federal brasileiro: Justiça do Trabalho, Justiça Federal, Justiça Militar e Tribunais Superiores, e integra a carreira de analista judiciário. Suas atribuições são auxiliar os magistrados na efetivação das ordens judiciais, consoante o Código de Processo Civil (CPC), a Consolidação das Leis do Trabalho (CLT), a Lei de Execuções Fiscais, e outras. De acordo com o Regulamento da Central de Mandados da Subseção Judiciária de Porto Alegre (Cempa/RS), de 2005, em seu artigo 12, incumbe ao oficial de justiça avaliador: efetuar pessoalmente as citações, intimações, penhoras, arrestos e demais diligências próprias do seu ofício, certificando minuciosamente o ocorrido e/ou lavrando os respectivos autos; executar as ordens do juiz a que estiver subordinado no cumprimento do mandado e, no âmbito interno, as emanadas do juiz diretor do foro, do juiz coordenador e do diretor da Cempa, e solicitar aos supervisores da Cempa e às Varas Federais, sempre que for necessário, orientações pertinentes ao cumprimento dos mandados.

Em reuniões anteriores à pesquisa com representantes dos oficiais de Justiça, para a elaboração do projeto, destacaram-se alguns aspectos do trabalho desempenhado que estariam atingindo sua saúde: sobrecarga de trabalho causada pelas atribuições legais; violência urbana; perigo da relação com o cidadão a ser intimado pelo oficial; o trabalho em si, quando este apresenta situações de sofrimento psíquico ligado aos aspectos próprios do conteúdo da execução dos mandados, e, além disto, a questão da informatização da Justiça Federal brasileira, que traz consigo, para essa categoria de trabalhadores, o medo do esvaziamento de sua função, pois grande parte de suas atribuições deixaria de existir ou seria realizada através do computador.

Nesse contexto, os objetivos principais desta pesquisa foram estudar o trabalho desenvolvido pelos oficiais de Justiça de Porto Alegre e sua repercussão na saúde, avaliar aspectos da organização do trabalho relacionados ao processo de saúde-doença, além de correlacionar os problemas de saúde e de qualidade de vida dos trabalhadores à organização do trabalho. Para tanto, a população estudada foi a de oficiais de Justiça Federal lotados na Central de Mandados de Porto Alegre, com um total de 78 servidores.

\section{Trabalho e saúde}

Parte-se do pressuposto de que o trabalho ocupa posição central na sociedade. Segundo Dejours $(2004$, p. 18), "[...] o trabalho desempenha um papel essencial de formação do espaço público, pois trabalhar não é tão só produzir: trabalhar é, ainda, viver junto”. 
O mesmo autor afirma que o trabalho deve sempre ser pensado como social (Dejours, 2004). Assim, entendemos que é fundamental fazer uma breve retomada das transformações pelas quais a organização do trabalho vem passando, nos últimos tempos.

Essas mudanças começaram a ocorrer com Taylor, ao propor a organização científica do trabalho (com a proposta de divisão do modo operatório, divisão entre órgãos de concepção intelectual e execução e divisão dos homens). Depois, as alterações prosseguiram com Ford, com o método da racionalização da produção em massa, impondo o ritmo de trabalho pela inserção da esteira (Heloani, 2003). Ambos propõem estratégias para o reordenamento da subjetividade na produção.

Principalmente após a década de 1970, o mundo do trabalho tem vivenciado uma situação crítica. De acordo com Harvey (1992), esse é um período marcado pela transição do fordismo para a acumulação flexível. Essa nova perspectiva é contrária à rigidez do período anterior, com suas diversas formas de controle, mediante o uso da automação eletrônica.

De acordo com Merlo e Lapis (2005), nesse período nasce o modelo conhecido como toyotismo. "Passavam, assim, a ser adotadas novas formas de organização do trabalho e da produção inspiradas no sucesso da indústria japonesa" (Merlo \& Lapis, 2005, p. 25). Essa nova forma de organização apoia-se na flexibilidade dos processos de trabalho, dos mercados, dos produtos e dos padrões de consumo.

Segundo Antunes (2005), a reestruturação produtiva e a realidade produtiva apresentam descompasso em diversos países, demonstrando um caráter singular da expansão das novas técnicas de produção e flexibilização do trabalho. No Brasil, há uma combinação de elementos do fordismo junto a técnicas de produção flexível, que podem ser comparados a um modelo "Frankenstein", na medida em que coexistem num mesmo espaço de trabalho processos taylorizados e programa de qualidade total (Merlo \& Lapis, 2005).

A expansão do neoliberalismo, no final dos anos 1970, ditou a implementação da reestruturação produtiva, com a privatização acelerada, o enxugamento do Estado e a sintonização das políticas fiscais e monetárias com os organismos mundiais de controle de capital. Para Antunes (1998), a crise que se abateu no mundo do trabalho nesse período "[...] afetou tanto a materialidade da classe trabalhadora, a sua forma de ser, quanto a sua esfera mais propriamente subjetiva, política, ideológica, dos valores e do ideário que pautam suas ações e práticas concretas". A desmontagem dos direitos sociais dos trabalhadores, o combate ao sindicalismo e a exacerbação do individualismo são consequências desse período.

Há hoje um forte movimento de descoletivização ou de reindividualização, que é avesso aos coletivos, às organizações sindicais, aos direitos trabalhistas e aos mecanismos de proteção sociais. Para Castel (1998), faz-se necessária uma reorganização das formas de intervenção do Estado. Essa seria a maneira de encontrar novas garantias de interesse coletivo, em contraponto aos interesses privados. Para o autor, houve uma retirada dos suportes sociais, junto à desregulamentação das relações de trabalho, refletidas no aumento do desemprego e do trabalho precário. Sua proposta seria a de que os direitos sociais fossem ligados ao trabalho, e não ao emprego, pois, na situação de desemprego ou de formas de contrato precárias, os trabalhadores não perderiam seus direitos. Acredita que a proteção social possibilita, para uma parcela da população, condições mínimas para sua independência social.

De acordo com Nardi e Tittoni (2011), mesmo que alguns autores apontem a perda da centralidade do trabalho, as transformações ocorridas na contemporaneidade demonstram que o trabalho permanece central na estrutura social e na "construção material e psíquica dos sujeitos".

Castel (1998) ressalta que a flexibilização tem atravessado a maior parte das instituições sociais, não só o trabalho, mas a família também, e que essa flexibilização tem 
trazido certa degradação, tanto da ordem do trabalho como da família, com custos econômicos e psicológicos, entre outros.

Para Dejours (2004), o agravamento do sofrimento psíquico no trabalho está ligado à evolução da organização do trabalho. Houve uma substituição dos métodos do taylorismo e do fordismo pela "avaliação individualizada dos desempenhos", com "[...] entrevistas de avaliação, auditagens internas e externas, contratos individualizados de objetivos, gestão por objetivo, balanço de competências, centro de resultados, autocontrole e autoavaliação, entre outros" (Dejours, 2004, pp. 18-19). Segundo o autor, isso colocou em concorrência, inclusive, os setores públicos com os privados, assim como os departamentos de uma mesma empresa, e todos os trabalhadores em um determinado local de trabalho.

Entendemos que é possível a transformação do sofrimento em prazer, a partir do reconhecimento. Mas, se "[...] falta reconhecimento, os indivíduos engajam-se em estratégias defensivas para evitar a doença mental, com sérias consequências para a organização do trabalho, que corre o risco de paralisia" (Dejours, 2004, p. 77).

O reconhecimento é algo que não pode ser prescrito na organização do trabalho e essa temática é recorrente em muitos outros momentos, além dos apresentados nos relatos dos trabalhadores. Segundo Dejours (2004), existe um reconhecimento de estética, de beleza, sobre o trabalho bem realizado, que é feito pelos pares, e existe um reconhecimento de utilidade, basicamente hierárquico.

Para que os trabalhadores possam realizar trocas sobre o trabalho, é necessário que existam espaços para a fala, para pensar sobre o cotidiano do trabalho. Segundo Dejours (1999), para que o espaço coletivo de discussão aconteça, a palavra deve ser "autêntica". Nesse sentido, é preciso realizar uma discussão sobre a organização do trabalho entre os trabalhadores que estão envolvidos diretamente com o processo de trabalho. Segundo o autor, "[...] o sofrimento está sempre ligado à degradação das condições de discussão e de intercompreensão" (Dejours, 1999, p. 171).

Os espaços de troca entre os trabalhadores, os períodos para as conversas, mesmo que informais, têm sido cada vez mais escassos. Os "poros" na jornada de trabalho, onde são realizadas as trocas verdadeiras sobre quem sabe do real do trabalho, têm sido suprimidos pela organização do aumento da produção em detrimento da qualidade e do bem-estar do trabalhador.

Sennet (2003) coloca que o trabalho, na atualidade, expressa a corrosão das relações, trazendo consigo angústia e um sentimento de estar à deriva, e o único caminho para o sujeito é o da solidão. As pessoas trabalham juntas, mas não há confiança, unem-se para a realização das tarefas, mas não permanecem unidas. Os indivíduos vivenciam um sentimento de esvaziamento moral, social, cultural ou político, já que não existe construção partilhada com os outros.

A atual organização do trabalho coloca os trabalhadores "uns contra os outros", quando não permite que possam solidariamente realizar as tarefas propostas em dupla ou no coletivo. As pessoas devem competir para conseguir alcançar o estabelecido e para manter-se trabalhando.

Em relação às adversidades presentes no trabalho e às condições de vida desestabilizantes, os trabalhadores têm de resistir e, novamente, estabilizar o que se desorganiza. A partir da habilidade, da inteligência e da astúcia, os trabalhadores constroem estratégias defensivas, que permitem a permanência da normalidade.

De acordo com Dejours (1999), não há passividade, as pessoas se defendem e constroem estratégias específicas no trabalho e, por essa razão, podem não adoecer. Partindo desse pressuposto, a normalidade pressupõe a existência de sofrimento.

\section{4}


Então, as estratégias são as reações construídas pelos trabalhadores, para enfrentamento e proteção contra as situações de risco e consequente sofrimento no trabalho. Essas estratégias podem ser tanto da ordem individual quanto coletiva; sendo que o mais interessante é que se o sofrimento é singular, individual, as pessoas cooperam para se defender, pois a superação pode ser coletiva (Dejours, 1999).

A estratégia de defesa coletiva é sustentada por um consenso e surge a partir das pressões organizacionais do trabalho. Ao mesmo tempo, traz ao sujeito uma estabilidade, uma harmonização que ele seria incapaz de conseguir individualmente (Dejours \& Abdoucheli, 1994).

Segundo Dejours (1999), se o sofrimento no trabalho não é sempre seguido de adoecimento é porque foram desenvolvidas estratégias de defesa eficazes para lidar com esse sofrimento. Vale salientar que as estratégias de defesa são específicas, características de um trabalho e relativas àquele grupo específico de trabalhadores. Isso ocorre, pois, para poder suportar as pressões do seu trabalho, são construídas estratégias para essas pressões. Dejours (1999) também afirma que as estratégias construídas avançam sobre a vida privada do trabalhador e essa mudança no funcionamento psíquico não fica restrita ao ambiente de trabalho.

\section{Procedimentos metodológicos}

A proposta de realização da pesquisa foi apresentada aos oficiais de Justiça, na Central de Mandados. Inicialmente, o Sindicato apresentou a proposta fruto das discussões ocorridas, esclarecendo a fase quantitativa e qualitativa e seu período de execução. O Coordenador do Laboratório da UFRGS, junto com uma pesquisadora, apresentou a metodologia da Psicodinâmica do Trabalho e a sugestão de realização dos grupos. Entre os trabalhadores presentes nas reuniões, 20 se mostraram interessados em participar das discussões em grupo e, nesse mesmo dia, foi marcado o início da atividade dos grupos e seu horário. Também nessas reuniões, 71 trabalhadores responderam o questionário proposto.

Os sujeitos pesquisados foram os oficiais de Justiça Federal, 78 servidores no total, lotados na Central de Mandados de Porto Alegre.

Optou-se pelo uso combinado de duas metodologias, uma quantitativa e outra qualitativa, com a intenção de permitir uma complementação das informações obtidas e uma melhor apreensão da realidade de trabalho encontrada.

Para a coleta de dados da abordagem quantitativa foram utilizados dois instrumentos:

-Um questionário estruturado, que contempla questões que abordam aspectos: sóciodemográficos, ocupacionais, de saúde-doença e de qualidade de vida do trabalhador.

- O Self Report Questionnaire (SRQ-20), para pesquisar a incidência de distúrbios psiquiátricos menores, que permite a comparação com estudos realizados com outras categorias de trabalhadores e com a população em geral.

A análise do banco de dados ocorreu por meio da construção das frequências e percentuais das respostas obtidas, com uma posterior interpretação dos dados.

A abordagem qualitativa ocorreu através do uso da metodologia em Psicodinâmica do Trabalho (PdT) (Dejours, 2004; Merlo \& Mendes, 2009). Tal metodologia é calcada na palavra do sujeito em situação de grupo, em um ambiente no qual este possa expressar sua vivência e elaborar, de maneira compartilhada, uma reflexão sobre a relação entre sofrimento e prazer no trabalho, através da identificação e análise das estratégias coletivas de defesa. 
Foi realizada uma pesquisa inicial para acesso aos documentos, ao local de trabalho, aos setores e à história da organização, para compreender o que os trabalhadores falaram durante os encontros. Ao mesmo tempo, foi analisado o Regulamento da Cempa, que estabelece objetivos, atribuições, competências, entre outras, atinentes ao exercício das atividades. Também foi realizada entrevista com a Coordenação da Cempa para conhecimento do histórico e das relações de trabalho. A intenção foi reunir informações que são úteis, posteriormente, para a interpretação das falas sobre os processos, mudanças e organização do trabalho.

A pesquisa propriamente dita consistiu na reunião de um grupo de trabalhadores, com a intenção de falar sobre o trabalho. Após os esclarecimentos, todos os trabalhadores interessados se dispuseram a participar da pesquisa, assinaram o Termo de Consentimento Livre e Esclarecido. A pesquisa foi aprovada pelo Comitê de Ética em Pesquisa do Instituto de Psicologia, da UFRGS.

As reuniões foram realizadas em horário e local combinado previamente com os participantes, com duração de aproximadamente uma hora e meia, semanalmente, e tiveram, em média, a participação de 10 trabalhadores. De acordo com a PdT, como o foco está nas formulações coletivas, não há impedimento que, de um encontro para outro, haja variação na participação dos elementos constituintes do grupo, muitas vezes por exigências e particularidades do próprio trabalho. No total foram realizados 5 encontros, os quais foram gravados para posterior transcrição. Para a avaliação qualitativa os comentários verbais dos trabalhadores foram agrupados por assuntos. Um mesmo assunto apareceu em diferentes encontros e, por isso, foi inserido no mesmo agrupamento. Os grupos concentraram as discussões em determinados temas, definidos a partir da própria fala dos participantes. $\mathrm{O}$ mesmo tema foi retomado várias vezes, por ser considerado importante para o momento ou por significar uma reelaboração de algo já discutido anteriormente.

A análise apresentada foi dividida em dois agrupamentos de comentários verbais relativos às dificuldades e/ou problemas presentes no trabalho: em relação à instituição e em relação à atividade (oficial de Justiça). Nesses agrupamentos foram formulados subgrupos ou categorias.

No primeiro agrupamento, em relação à instituição, estão reunidas questões relativas à instituição Justiça Federal e seus desdobramentos. No segundo, em relação à atividade, são apresentadas as relações estabelecidas nesse trabalho e a organização do trabalho na Cempa, bem como as construções de estratégias para a manutenção da saúde psíquica desses trabalhadores no exercício de sua atividade.

Ao final dos encontros foi realizada uma primeira restituição, com o objetivo de fazer a validação do material obtido e das interpretações feitas. A análise do material foi feita a partir das fundamentações teóricas da Psicodinâmica do Trabalho, sempre levando em conta as particularidades da organização do trabalho e a subjetividade dos trabalhadores envolvidos e procurando identificar as formas de reconhecimento no trabalho cotidiano.

Além da validação necessária no decorrer da pesquisa, ao seu término foi produzido um relatório, que deu origem a este artigo, e que foi entregue aos trabalhadores e ao Sintrajufe-RS, para que, a partir de uma leitura crítica do material produzido, pudessem concordar ou discordar dos levantamentos feitos e sentir-se mais instrumentalizados para propor modificações na organização do trabalho, que levem a uma melhor qualidade de vida. 


\section{Resultados}

Do total de 78 oficiais de Justiça lotados na Central de Mandados de Porto Alegre, 71 responderam ao questionário, sendo que, destes, 63,4\% têm idades entre 46 e 60 anos, o que demonstra que este é um grupo de meia-idade, próximo ao período de afastamento por aposentadoria. Nessa amostra, a maioria dos participantes eram homens $(54,3 \%)$, e 54,9\% eram casados. Em relação ao tempo de trabalho no judiciário, 67,6\% do grupo têm mais de 16 anos de atuação nesse local.

Entende-se que estudar apenas as patologias diagnosticáveis produziria um resultado muito aquém da verdadeira situação de saúde desses servidores. Pode-se dizer que as patologias diagnosticáveis são a pequena parte visível de um enorme iceberg, que esconde sob a água uma parte muitas vezes maior, que é o sofrimento psíquico relacionado ao trabalho. Para se poder estabelecer políticas de promoção e prevenção à saúde adequadas no trabalho, é necessário identificar, da forma mais precoce possível, as fontes da agressão à saúde que possam levar ao adoecimento e que não são visíveis aos instrumentos tradicionais da clínica médica ou psicológica.

A falta de reconhecimento pela instituição do trabalho realizado é uma das principais questões apresentadas pelos oficiais. Ao mesmo tempo, relatam que outras instituições públicas e a sociedade em geral não conhecem e, portanto, não reconhecem seu trabalho.

Os oficiais ressentem-se por ser desconsiderados, publicamente, por quem esperavam que os reconhecessem. Também colocam que a falta de respaldo e até mesmo a desautorização para a realização de seu trabalho está diretamente relacionada à falta de reconhecimento. As colocações em relação ao respaldo para a realização do trabalho, muitas vezes, dizem respeito apenas a ser escutados nas suas necessidades ou ser orientados à realização de um mandado. Pois, se não são reconhecidos, não há como a instituição entender as necessidades inerentes à função.

O reconhecimento no trabalho é indispensável para a construção do equilíbrio psíquico e isso não vem ocorrendo de forma adequada. Esse reconhecimento não se dá, inicialmente, sobre a pessoa do trabalhador, mas sobre o próprio trabalho. É o trabalho que é julgado e, secundariamente, o julgamento recairá sobre quem o fez. $O$ reconhecimento pode ser produzido por pares (colegas), mas, no caso da atividade exercida pelos oficiais de Justiça, deve ocorrer pela chefia imediata e, principalmente, pela chefia da qual emana a ordem para execução do trabalho, no caso, o juiz. Pelos relatos desses trabalhadores, praticamente não ocorrem contatos diretos com os juízes e eles se sentem sem possibilidades de construir referências sobre a qualidade de seu trabalho e sem condições de buscar amparo para as situações inesperadas que ocorrem em seu dia a dia.

Foi expresso pelo grupo um sentimento de desrespeito, por parte dos demais servidores, em relação ao exercício de sua atividade. Referem não conseguir dar visibilidade às tarefas realizadas que demandam tempo e muito desgaste psíquico. Exemplificam que, muitas vezes, a execução de um mandado pode demorar horas, ou mesmo dias, e coloca os oficiais em situações embaraçosas, perigosas e, muitas vezes, insalubres, não sendo computada essa qualidade do trabalho, apenas o número de mandados efetuados.

Ao mesmo tempo, estão associadas à falta de reconhecimento as escassas informações sobre o mandado, o que poderia ser diferente se houvesse maior intercâmbio de informações. $O$ funcionamento das Varas também é apontado como uma das dificuldades presentes no cotidiano. Muitas vezes, necessitam repetir um mesmo procedimento devido a erros na elaboração do mandado. Muitas vezes, mesmo sabendo que existe erro no mandado, não podem modificá-lo e são orientados a cumpri-lo mesmo sabendo do erro, o que pode trazer mais problemas futuros. 
Outra situação trazida pelo grupo é, muitas vezes, a falta de comunicação entre a Vara e a Central ou, ainda, a culpabilização do oficial e da Central por algo que já foi resolvido, mas que não foi registrado.

Os oficiais referem o caráter solitário como uma característica de seu trabalho na maioria dos encontros e também nas entrevistas realizadas. Em seus relatos, a solidão da atividade, aparece, muitas vezes, como uma sensação de desamparo. Essa, certamente, é uma peculiaridade desse tipo de atividade, que não iremos encontrar em outras categorias de servidor público. Porém, é importante não "naturalizar" esse aspecto, isto é, considerá-lo um pressuposto inerente ao tipo de atividade e sobre o qual não é possível realizar uma intervenção e uma prevenção das agressões à saúde psíquica daí decorrentes.

Em alguns momentos, o próprio grupo coloca a possibilidade da realização de algumas atividades em dupla, mas essa situação faz com que alguém seja sobrecarregado na medida em que cada um tem uma carga de trabalho a cumprir. Dão-se conta de que muitas vezes dividindo o mesmo espaço de trabalho não sabem o que acontece com seus colegas no cotidiano. Além de a tarefa ser executada individualmente, sentem a necessidade de realizar trocas entre os pares. Porém, como não há um espaço para essas trocas, a própria atividade faz com que cada vez mais sejam levados ao individualismo e a não buscar o contato entre os colegas.

A falta de um treinamento inicial para a execução da atividade também é apontada como um fator de sofrimento, na medida em que aprendem sozinhos ou apenas com algum colega (as respostas encontradas no questionário estruturado corroboram esses comentários, indicando que $90,1 \%$ dos oficiais de Justiça não receberam treinamento para a atividade. Dos $9,9 \%$ que afirmam ter recebido treinamento, apenas $12,5 \%$ - um oficial - foram treinados por curso oferecido pela administração, $75 \%$ - seis oficiais - foram treinados pelos próprios colegas e $12,5 \%$ indicaram outra forma). A ausência de uma política de educação continuada na instituição também é apontada como falha nas situações de mudança nas rotinas de trabalho, muitas vezes sem aviso prévio, para as quais os oficiais não são preparados com antecedência.

Nos relatos desses trabalhadores, é possível perceber que, para a instituição, a questão da violência a que estão expostos é considerada algo inerente à própria atividade. Há uma tendência à banalização, quase a uma "naturalização". No entanto, existem várias atividades nas quais os trabalhadores podem estar expostos a risco de violência e nas quais, diferentemente das forças policiais, não há uma preocupação de treinamento e prevenção constante. No caso dos oficiais de Justiça Federal, não há nenhum tipo de treinamento específico nem são tomadas medidas que possam limitar os riscos de exposição à violência.

Em relação ao Self Report Questionnaire (SRQ-20), os resultados indicaram um percentual elevado de distúrbios psiquiátricos menores (DPMs) nessa população, atingindo 50,7\%. Maior que o encontrado nos servidores dos Juizados Especiais Federais, que foi de $37,1 \%$, ou entre os servidores dos Gabinetes do TRT, 30,9\%, ou o estudo populacional realizado na cidade de Pelotas-RS, que indicou 28,5\% de DPMs (Lautert, Merlo, Souza Filho, Dornelles, Paz, Pai et al., 2009). Como citado anteriormente, o SRQ-20 é apenas uma pista das condições visíveis do sofrimento psíquico produzido pelo trabalho. Nesse caso, ele corrobora os achados já descritos a partir do uso da Psicodinâmica do Trabalho. Usando, ainda, a imagem do iceberg, esses resultados indicam que está havendo uma emergência das agressões à saúde para um nível de diagnóstico (ou pré-diagnóstico). Essa afirmação é reforçada pelo percentual de $7,1 \%$ que responderam ter tido ideias de acabar com a própria vida e de $8,6 \%$ que se sentem incapazes de desempenhar um papel útil em sua vida, indicando prováveis casos de depressão grave e iniciativas suicidas.

O grupo participante da pesquisa apresenta uma pequena preponderância de mulheres, em sua grande maioria casados ou em união estável, trabalhando há mais de 10 anos no Judiciário e com um importante aumento na carga de trabalho nos últimos anos. Esses dados indicam uma população com experiência de vida e de Judiciário, fato que os possibilita ter uma

\section{8}


maior percepção das modificações ocorridas no trabalho desde o período em que entraram na instituição, como, por exemplo, os que indicam um aumento da quantidade de trabalho $(89,2 \%)$ e uma maior dificuldade para realizar o trabalho $(97,0 \%)$.

O aumento da dificuldade para realizar o trabalho foi produzido por aspectos ligados diretamente à organização do trabalho (aumento da quantidade de processos, redução da quantidade de servidores), mas, também, a aspectos que tocam à população como um todo (violência urbana, trânsito congestionado, dificuldade para chegar ao destinatário). Os aspectos ligados à organização do trabalho são passíveis de modificação a partir de iniciativas da instituição e dos próprios oficiais de Justiça. Os aspectos mais gerais ligados a questões de trânsito e violência urbana, apesar de estar fora do controle da instituição, não podem ser considerados uma fatalidade e, teoricamente, "cobertos" pelo salário recebido por esses trabalhadores. Situações de risco à vida presentes na atividade devem ser levadas em consideração pela instituição e proposições devem ser feitas para aumentar a proteção desses trabalhadores, pois $65,7 \%$ sofreram algum tipo de acidente ou agressão, $81,7 \%$ sentiram-se ameaçados e $18,8 \%$ foram efetivamente agredidos no exercício da função. Completando esses elevados números, $63,8 \%$ tiveram bens danificados e 38,8\%, tiveram bens roubados quando cumpriam seu trabalho.

As questões da atividade solitária e de risco aparecem conjuntamente. Os oficiais relatam que a insegurança para a realização de sua atividade na rua tem aumentado e não há respaldo institucional. Há uma sensação de insegurança para sair na rua, que não é apenas do oficial de Justiça, mas da sociedade em geral. O que ocorre é que esses trabalhadores, como não sentem seu trabalho reconhecido, sentem-se ainda mais inseguros pela hostilidade das pessoas e, também, pela falta do respaldo da instituição. Muitas vezes, também são ameaçados e agredidos quando tentam cumprir os mandados.

Apesar de a atividade estar prevista como atividade de risco, não há um adicional de risco para seu exercício. Ao mesmo tempo, ela não é reconhecida como tal. Quando a situação vivida foi algo muito forte para o oficial, aparece a dificuldade de relatar o sofrido na certidão, pois é uma rememoração do que aconteceu. Com a situação de risco presente no cotidiano também aparecem algumas situações que causam sofrimento, principalmente quando as pessoas a ser intimadas têm situações financeiras difíceis, estão doentes, ou questões semelhantes.

A atividade realizada por esses trabalhadores leva diretamente a conflitos éticos e, muitas vezes, a um grande sofrimento. Acreditamos que esses oficiais de Justiça compreendem perfeitamente a necessidade de seu trabalho para o bom andamento do poder judiciário no Brasil. Porém, seria uma ingenuidade pensar que isso pode ser feito sempre sem nenhum tipo de geração de ansiedade. A questão que se coloca é a seguinte: que tipo de apoio esses servidores podem e devem receber da administração para ter sua saúde psíquica razoavelmente protegida no exercício de sua função? Consequências do tipo Estresse Pós-traumático são frequentes em atividades desse tipo e é necessário que seja disponibilizado um espaço qualificado de apoio onde possam verbalizar seus sentimentos, de forma a evitar processos de cronificação daí decorrentes.

Como não há um espaço para discussão das mudanças ocorridas no processo de trabalho, o processo eletrônico torna-se algo desconhecido que virá a acontecer, mas que não se sabe quando e de que forma.

Está a mudar. Nós estamos num período de adaptação, de transição.

As mudanças provenientes do processo eletrônico vão fazer que algumas das atividades dos oficiais sejam realizadas de forma eletrônica, e há a possibilidade de que algumas funções sejam extintas. 
A falta de um coletivo, já referida anteriormente, apareceu, também, nos resultados quantitativos. Esses oficiais de Justiça têm o sentimento de realizar um trabalho individual, sem pertencimento a um grupo e de que as cobranças são feitas sobre o indivíduo isoladamente. A constituição de um coletivo de trabalhadores é considerada um instrumento fundamental para proteção da saúde mental dos indivíduos no trabalho, pois será nesse espaço que poderão ocorrer os julgamentos dos pares e as possíveis propostas de modificação dos aspectos considerados mais nocivos à saúde mental. A maior parte do grupo afirma que seria importante um espaço permanente de discussão, relativo aos procedimentos a ser construídos coletivamente, para o bom andamento do trabalho. Esses profissionais gostariam de estabelecer um espaço de discussão de seus sentimentos, sobre os problemas, sobre suas dificuldades no atendimento às demandas do trabalho.

Os espaços de discussão são considerados, pela Psicodinâmica do Trabalho, fundamentais para que se possa construir condições para o exercício do reconhecimento e para que possam ser incorporadas novas formas de trabalhar. No mundo do trabalho real, isto é, quando da execução da tarefa, são necessários vários "artifícios" para que ele possa ocorrer nas condições e nos períodos adequados. Nesses momentos, o trabalhador precisa, muitas vezes, burlar o que foi prescrito e "inventar" suas próprias soluções. Esse espaço de encontro - que a Psicodinâmica do Trabalho chama de um "espaço público" - é fundamental para que haja o necessário reconhecimento (ou não) do que foi "inventado", para que se possa, através do reconhecimento dos pares (colegas) e/ou da chefia, produzir o prazer e a saúde no trabalho. $\mathrm{Na}$ atividade desses trabalhadores podem ser encontrados alguns desses momentos durante os plantões, porém, os plantões reúnem um pequeno número de oficiais de Justiça. O melhor seria poder dispor de um espaço formalizado e designado para tal. Assim como não há um espaço formal para trocas entre os trabalhadores, também não há uma participação nas mudanças ocorridas nos processos de trabalho.

Os resultados também indicam um sistema de avaliação que não conta com o trabalhador em sua elaboração, voltado para as quantidades e os prazos dos mandados realizados, não existindo espaço para o diálogo e a participação nas definições sobre o trabalho ou para os aspectos qualitativos da atividade realizada. O principal problema das avaliações individualizadas e apenas quantificadas é o fato de elas não medirem o trabalho em si, mas apenas os resultados do trabalho. Isso fica evidente no caso desses trabalhadores. O cumprimento de um mandado pode ser feito rapidamente ou pode levar vários dias. E existe muito trabalho que ainda deve ser feito após a efetivação da tarefa em si. Esses outros trabalhos não são levados em conta pela instituição. Da mesma forma, o "custo" subjetivo envolvido em cada uma das atividades não é levado em consideração e passa a ser considerado "natural" e inerente à atividade de oficial de Justiça.

A atividade é considerada extenuante por todos os participantes do grupo. Apesar de nem sempre estar associada ao adoecimento, o cansaço no corpo e o mental são apontados como reflexos do que é executado no dia a dia. Os relatos do cansaço e da fadiga em muitos momentos vêm permeados com falas sobre doenças, estresse e irritação.

Há uma grande preocupação sobre o futuro do trabalho para os oficiais de Justiça. Como a maioria das mudanças não são discutidas e os trabalhadores só ficam sabendo quando já serão implantadas, há uma tensão sobre quais mudanças afetarão o trabalho. As aposentadorias que estão por vir e o aumento da carga de trabalho preocupam os oficiais, já que não há uma previsão da reposição por novos profissionais Quando há uma situação de férias ou de licença, por mais que exista uma organização por escala e substituição na zona, as pessoas se sentem sobrecarregadas e sem saber se conseguirão executar aquilo que está previsto.

Os resultados apontaram, também, um bom grau de satisfação por trabalhar como oficiais de Justiça. Porém, quando se observam os motivos para esse bom grau de satisfação, veremos que eles não estão, na sua grande maioria, relacionados ao trabalho em si, mas, 
principalmente, a aspectos externos à atividade que exercem: salário $(94,3 \%)$; estabilidade $(87,3 \%)$; benefícios oferecidos (42,2\%); jornada de trabalho $(28,1 \%)$; e apenas $18,3 \%$ pelas atividades e pelas tarefas. O significado disso é que os aspectos diretamente relacionados ao trabalho, fundamentais para a construção da identidade e a saúde psíquica, não são referidos como elemento de satisfação pela grande maioria desses trabalhadores. O salário e os benefícios certamente são importantes para uma boa qualidade de vida, mas não são suficientes para permitir o reconhecimento do trabalho que realizam.

Isso também pode ser encontrado quando instados a responder quais são os motivos que menos os motivam a trabalhar no Judiciário: citam o desconhecimento pelos demais servidores das atividades que eles realizam $(83,0 \%)$, as dificuldades no relacionamento com o executado $(42,2 \%)$, a política de treinamento $(30,9 \%)$, a falta de possibilidade de crescimento $(28,1 \%)$, a desvalorização social $(23,9 \%)$, problemas de trânsito $(26,7 \%)$ as atividades e tarefas $(21,1 \%)$ como principais razões de descontentamento.

Todas essas questões vão se refletir no importante percentual de servidores que utilizam antidepressivos $(36,1 \%)$, medicamentos para dormir $(19,1 \%)$ ou que necessitam de ansiolíticos $(19,1 \%)$.

Além de algumas estratégias apontadas pelo grupo, como possibilidade de superação das dificuldades encontradas no cotidiano, está presente o não envolvimento com as questões mais gerais do grupo de trabalho, aparecendo o silenciamento. $O$ silenciamento tem sido um movimento da sociedade, não só em relação ao trabalho, mas a todos os espaços de discussão. $\mathrm{Na}$ retração dos trabalhadores e em sua condição de não falar, o preocupante é que o silêncio não produz soluções. Ele afasta, cada vez mais, o sujeito de qualquer processo possível de relação.

Então, os trabalhadores lançam estratégias como forma de "amenizar" as situações vividas, mesmo que momentaneamente.

[...] quer dizer, eu também tenho emoções, eu tenho que seguir em frente... como é que eu sigo em frente?

Esses resultados fazem parte da "ponta do iceberg". É a parte visível e identificável do sofrimento psíquico provocado pelo trabalho nesses oficiais de Justiça. As intervenções para a modificação dessa situação, no entanto, não podem levar em consideração apenas esses aspectos "visíveis". Precisam voltar-se, necessariamente, para as fontes do sofrimento, que são todos os aspectos relacionados à organização do trabalho.

\section{Considerações finais}

Diante do exposto, apresentamos algumas recomendações que podem trazer modificações no cotidiano do trabalho e ser benéficas à saúde no trabalho dos oficiais:

- Sugere-se a criação de um espaço de reunião e discussão entre os trabalhadores, a coordenação e os juízes, preferencialmente, com a participação de profissionais da Psicologia da instituição, caracterizando-se como uma ação permanente para essa equipe (de Psicologia) e um canal de comunicação da coordenação com todos os trabalhadores.

- Sugere-se o estabelecimento de uma política de educação continuada para que esses profissionais possam enfrentar melhor as adversidades de seu cotidiano. 
- Sugere-se um trabalho de conhecimento e de reconhecimento da atividade desempenhada pelo oficial de Justiça dentro da própria instituição, redimensionando o lugar que esse profissional ocupa para os demais trabalhadores envolvidos em seu processo de trabalho.

- A carga de trabalho aparece, também, como fator importante no sofrimento no trabalho, o que leva a pensar que a diminuição do quadro atual de profissionais, poderá revelar-se nociva à saúde no trabalho. Por essa razão, acreditamos que a possibilidade de redução do número de trabalhadores deve merecer um estudo mais pormenorizado em relação às cargas de trabalho e às modificações que ocorrerão na execução das atividades. Os resultados desta pesquisa levam a crer que uma diminuição do número de oficiais de Justiça na Central de Mandados de Porto Alegre poderá agravar, ainda mais, as agressões à saúde física e psíquica desses trabalhadores.

Consideramos que as agressões à saúde dos oficiais de Justiça encontradas nesta pesquisa são, em sua grande maioria, passíveis de ser eliminadas ou, pelo menos, reduzidas. Para isso, é necessário que a instituição possa acolher os resultados deste estudo de forma aberta e inicie, imediatamente, um processo de discussão com esses trabalhadores, para buscar caminhos para tratar esses problemas.

Algumas soluções não necessitam de maiores investimentos financeiros e podem ser encontradas a partir da criação de um simples espaço permanente de escuta. Outras talvez demandem mais tempo e recursos. Mas, partindo-se do pressuposto de que o trabalho deve ser um espaço de realização, de reconhecimento e, sempre que possível, de felicidade e que os aspectos complementares, tais como valor de salário ou estabilidade no emprego, não são suficientes para promover uma boa qualidade de vida no trabalho, a busca de soluções estará plenamente justificada. E, certamente, permitirá uma ação muito mais efetiva da atividade exercida pela Justiça Federal brasileira.

\section{Referências}

Antunes, R. (1998). As dimensões da crise no mundo do trabalho. Olho da História: Revista de História Contemporânea, 4.

Antunes, R. (2005). Os sentidos do trabalho: ensaio sobre a afirmação e a negação do trabalho. São Paulo: Boitempo.

Castel, R. (1998). As metamorfoses da questão social: uma crônica do salário. Petrópolis, RJ: Vozes.

Dejours, C. (1999). Conferências brasileiras: identidade, reconhecimento e transgressão no trabalho. São Paulo: FGV.

Dejours, C. (2004). Avant-propos para a edição brasileira. Addendum: da psicopatologia à psicodinâmica do trabalho. In S. Lancman \& L. I. Sznelwar (Orgs.), Christophe Dejours: da psicopatologia à psicodinâmica do trabalho. Rio de Janeiro: Fiocruz.

Dejours, C. \& Abdoucheli, E. (1994). Itinerário teórico em psicopatologia do trabalho. In Dejours, C., Abdoucheli, E. \& Jayet, C. Psicodinâmica do trabalho: contribuições da Escola Dejouriana à análise da relação prazer, sofrimento e trabalho. São Paulo: Atlas.

Ellwanger, M. C. (2009). Autogestão e trabalho em equipe na atuação do oficial de Justiça Federal. Monografia de Conclusão de Curso, Pós-Graduação em Gestão do Capital Humano, Faculdade Porto-Alegrense, Porto Alegre.

Harvey, David. (1992). Condição pós-moderna: uma pesquisa sobre as origens da mudança cultural. São Paulo: Loyola.

Heloani, J. R. (2003). Gestão e organização do capitalismo globalizado: história da manipulação psicológica no mundo do trabalho. São Paulo: Atlas.

Lautert, L., Merlo, A. R .C., Souza Filho, G. A., Dornelles, R. A. N., Paz, A. A., Pai, D. D. et al. (2009). Repercussões do trabalho virtual do Juizado Especial Federal do Rio Grande do Sul na saúde do trabalhador (relatório de pesquisa). Porto Alegre: [s. n.].

Merlo, A. R. C. \& Mendes, A. M. B. (2009). Perspectivas do uso da psicodinâmica do trabalho no Brasil: teoria, pesquisa e ação. Cadernos de Psicologia Social do Trabalho, 12 (2), 141-156.

Merlo, A. R. C. \& Lapis, N. L. (2005). A saúde e os processos de trabalho no capitalismo: algumas considerações. Boletim da Saúde: Saúde do Trabalhador, 19 (1), 17-29.

Nardi, H. C. \& Tittoni, J. (2011). Subjetividade e trabalho. In A. D. Cattani (Org.), Dicionário de trabalho e tecnologia (pp. 375-382). Porto Alegre: Zouk. 
Sennet, R. (2003). A corrosão do caráter: consequências pessoais do trabalho no novo capitalismo. Rio de Janeiro: Record.

\section{Endereço para correspondência}

merlo@ufrgs.br, carlabott@terra.com.br

Recebido em 16/05/2011

Revisado em 05/03/2012

Aprovado em 05//05/2012 